\title{
ЛИТЕЙНЫЕ И МЕТАЛЛУРГИЧЕСКИЕ ПРОЦЕССЫ
}

\section{Н. А. Кидалов, Н. В. Григорьева, А. В. Орлова}

\section{ИССЛЕДОВАНИЕ ВЛИЯНИЯ ОЩЕЛАЧЕННЫХ ЛИГНОСУЛЬФОНАТОВ ТЕХНИЧЕСКИХ НА ФИЗИКО-МЕХАНИЧЕСКИЕ И ТЕХНОЛОГИЧЕСКИЕ СВОЙСТВА ЖИДКОСТЕКОЛЬНЫХ СМЕСЕЙ}

\author{
Волгоградский государственный технический университет \\ e-mail:mitlp@vstu.ru
}

В работе представлены результаты исследования влияния ощелаченных лигносульфонатов технических на физико-механические и технологические свойства жидкостекольных смесей. В результате исследования выбран состав, при котором достигается наименьший показатель остаточной прочности. С помощью двухлучевого электронного сканирующего микроскопа «Versa 3D» рассмотрена структура жидкостекольных пленок на огнеупорном кварцевом наполнителе с целью выявления дефектов, обеспечивающих снижение остаточной прочности.

Ключевые слова: кварцевый песок, поверхность зерна, водный раствор силиката натрия, жидкое стекло, остаточная прочность, лигносульфонаты технические.

\section{N. A. Kidalov, N. V. Grigorieva, A. V. Orlova}

\section{RESEARCH OF THE INFLUENCE OF LEALED TECHNICAL LIGNOSULPHANATES ON THE PHYSICAL-MECHANICAL AND TECHNOLOGICAL PROPERTIES OF LIQUID-GLASS MIXTURES}

Volgograd State Technical University

The paper presents the results of a study of the effect of technical alkalized lignosulfonates on the physicomechanical and technological properties of liquid glass mixtures. As a result of the study, a composition was selected that achieved the lowest residual strength. Using a two-beam scanning electron microscope "Versa 3D", the structure of liquid glass films on a refractory quartz filler is examined with the aim of defects that provide a decrease in residual strength.

Keywords: quartz sand, grain, aqueous sodium silicate solution, liquid glass, residual strength, technical lignosulfonates.

В настоящее время жидкое стекло является одним из распространенных связующих материалов при изготовлении формовочных и стержневых смесей для литейного производства, что связано с рядом его положительных качеств, таких как нетоксичность, относительно низкая стоимость, высокая связующая способность и т. Д. [1,2].

Для получения смесей с заданными свойствами необходимо особое внимание уделять качеству используемых исходных материалов. Наличие различных примесей на поверхности зерен огнеупорного наполнителя, шерохова- тость поверхности оказывают большое влияние на исходную прочность жидкостекольных смесей. В связи с этим следует уделять внимание активации поверхности, причем не только наполнителя, но и добавок, введение которых необходимо для обеспечения требуемого уровня технологических свойств смесей. При этом необходимо учитывать сложность выбивных операций после заливки металла в форму [3-4].

Из приведенных выше требований универсальным является введение в смесь недорогих органических добавок, обеспечивающих высокую исходную прочность жидкостекольных

(C) Кидалов Н. А., Григорьева Н. В., Орлова А. В., 2021 
смесей, а также снижающих остаточную прочность при высокотемпературном воздействии. Процесс разупрочнения при вводе данных добавок реализуется за счет выгорания органической части и (или) выделения газов $\mathrm{CO}$ и $\mathrm{CO}_{2}$. При этом внутри формы при выходе газов образовываются поры, сопровождающие нарушение целостности пленки связующего, что положительно скажется на выбиваемости жидкостекольных смесей [5-7]. Для достижения поставленных целей в данной работе в качестве добавки использовались лигносульфонаты технические (ЛСТ) - продукты переработки древесины, содержащие смесь натриевых солей лигносульфоновых кислот. ЛСТ обладают универсальными свойствами поверхностно-активных веществ, характеризующихся пластифицирующим и диспергирующим действием [4]. При использовании связующих на основе лигносульфонатов происходит снижение себестоимости годного сырья, уменьшение осыпаемости стержней, снижение температуры и сокращение времени теплового отверждения. Согласно работам Н. Х. Иванова [8-10] для повышения исходной прочности жидкостекольных смесей с добавлением ЛСТ необходимо предварительное ощелачивание связующего.

Целью данной работы является исследование влияния ощелаченных лигносульфонатов технических (ОЛСТ) на физико-механические и технологические свойства жидкостекольных смесей.

Ощелачивание лигносульфонатов технических проводили 34\%-м раствором едкого натра. В предварительно разбавленный водой ЛСТ до необходимой плотности вводили раствор щелочи в соотношении 100/30. Время выдержки составляло двое суток.

Для исследования влияния ощелаченных лигносульфонатов технических на физико-механические и технологические свойства жидкостекольных смесей были изготовлены жидкостекольные смеси с различным содержанием связующего, в качестве наполнителя для которых использовался кварцевый песок марки $1 \mathrm{~K}_{2} \mathrm{O}_{3} 03$. Состав смесей представлен в табл. 1 .

После приготовления смеси проходили исследование, включающее в себя определение технологических характеристик, таких как влажность, газопроницаемость, прочность (во влаж- ном состоянии), предел прочности как на сжатие, так и на разрыв, а также гигроскопичность и осыпаемость. Исследование образцов проводилось согласно методикам, установленным в соответствующих ГОСТах [11-12].

Таблица 1

Состав смесей

\begin{tabular}{|c|c|c|c|}
\hline \multirow{2}{*}{$\begin{array}{c}\text { Шифр } \\
\text { смеси }\end{array}$} & \multicolumn{3}{|c|}{ Состав смесей, мас. ч. } \\
\cline { 2 - 4 } & $\begin{array}{c}\text { Кварцевый песок } \\
1 \mathrm{~K}_{2} \mathrm{O}_{3} 03\end{array}$ & $\begin{array}{c}\text { Жидкое } \\
\text { стекло }\end{array}$ & $\begin{array}{c}\text { ОЛСТ } \\
\text { (сверх 100 мас. ч.) }\end{array}$ \\
\hline 1 & 97 & 3 & - \\
\hline 2 & 97 & 3 & 2 \\
\hline 3 & 97 & 3 & 3 \\
\hline 4 & 97 & 3 & 4 \\
\hline 5 & 96 & 4 & - \\
\hline 6 & 96 & 4 & 2 \\
\hline 7 & 96 & 4 & 3 \\
\hline 8 & 96 & 4 & 4 \\
\hline 9 & 95 & 5 & - \\
\hline 10 & 95 & 5 & 2 \\
\hline 11 & 95 & 5 & 3 \\
\hline
\end{tabular}

В табл. 2 представлены результаты физикомеханических и технологических свойств жидкостекольных смесей с добавлением ОЛСТ.

Согласно полученным результатам можно сделать вывод о том, что добавление ощелаченных лигносульфонатов технических положительно влияет на прочностные характеристики жидкостекольных смесей. Физико-механические свойства смесей соответствуют технологическим параметрам, обеспечивающим процесс изготовления форм и стержней.

Для определения остаточной прочности из исследуемых смесей были изготовлены стандартные цилиндрические образцы диаметром и высотой 0,05 м по ГОСТ 23409.7-78. Далее образцы выдерживались в муфельной печи модели ЭКПС-10 в течение 40 минут при температурах $180,400,600,800{ }^{\circ} \mathrm{C}$, что сопоставимо критическим температурным интервалам, приводящим к дегидратации связующего, и были испытаны на остаточную прочность путем сжатия образцов с помощью прибора РМ-500. На рис. 1-3 представлены результаты остаточной прочности образцов с различным содержанием силикатного связующего. 
Таблица 2

Физико-механические и технологические свойства жидкостекольных смесей с добавлением ОЛСТ

\begin{tabular}{|c|c|c|c|c|c|c|c|}
\hline \multirow{3}{*}{$\begin{array}{l}\text { Шифр } \\
\text { смеси }\end{array}$} & \multicolumn{7}{|c|}{ Свойства смесей } \\
\hline & \multirow{2}{*}{$\begin{array}{c}\text { влажность, } \\
\%\end{array}$} & \multirow{2}{*}{$\begin{array}{l}\text { газопрони- } \\
\text { цаемость, ед. }\end{array}$} & \multirow{2}{*}{$\begin{array}{c}\text { предел прочности, } \\
\sigma_{\mathrm{w}} \cdot \mathrm{MПа}\end{array}$} & \multicolumn{2}{|c|}{ предел прочности, $\sigma_{\mathrm{T}} \cdot \mathrm{MПа}$} & \multirow{2}{*}{$\begin{array}{c}\text { гигроскопич- } \\
\text { ность, \% }\end{array}$} & \multirow{2}{*}{$\begin{array}{c}\text { осыпаемость, } \\
\%\end{array}$} \\
\hline & & & & на сжатие & на разрыв & & \\
\hline 1 & 2,0 & 232,5 & 0,3 & 1,94 & 0,57 & 0,5 & 0,5 \\
\hline 2 & 2,5 & 236 & 0,56 & 2,50 & 0,59 & 1,0 & 0,45 \\
\hline 3 & 3 & 227,5 & 0,67 & 2,36 & 0,64 & 1,0 & 0,4 \\
\hline 4 & 3,5 & 212 & 0,73 & 1,92 & 0,63 & 1,5 & 0,3 \\
\hline 5 & 2,0 & 227,5 & 0,53 & 2,30 & 0,92 & 0,5 & 0,5 \\
\hline 6 & 3,0 & 250 & 0,64 & 2,45 & 0,54 & 0,5 & 0,45 \\
\hline 7 & 3,5 & 235 & 0,76 & 2,50 & 0,57 & 0,75 & 0,45 \\
\hline 8 & 4,0 & 240 & 0,72 & 2,44 & 0,40 & 1,0 & 0,4 \\
\hline 9 & 2,5 & 245 & 0,57 & 1,97 & 0,52 & 0,5 & 0,45 \\
\hline 10 & 3,5 & 243 & 0,66 & 2,50 & 0,62 & 0,1 & 0,3 \\
\hline 11 & 4,0 & 245 & 0,68 & 2,50 & 0,93 & 1,5 & 0,3 \\
\hline
\end{tabular}

Остаточная прочность, $\sigma_{\text {сж}} \cdot \mathrm{MПа}$

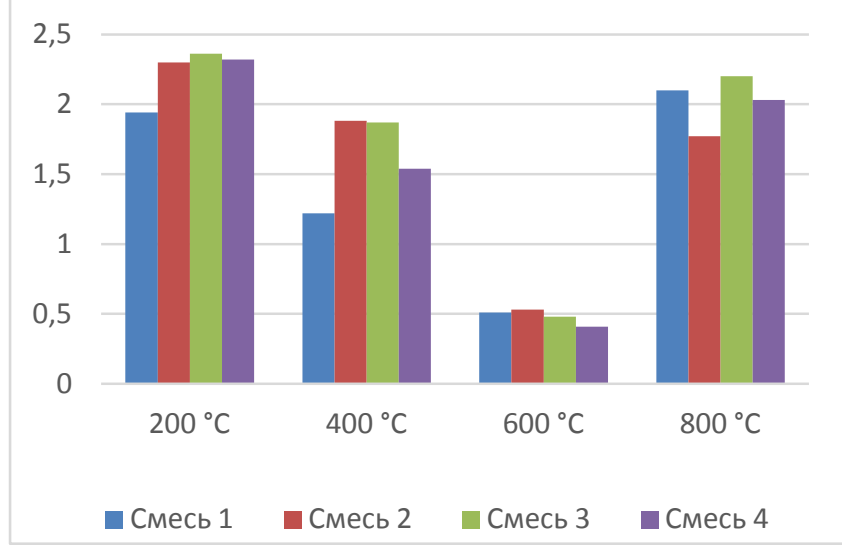

Рис. 1. Остаточная прочность жидкостекольных образцов при содержании $3 \%$ жидкого стекла

Остаточная прочность, $\sigma_{\text {сж }} \cdot \mathrm{MПа}$

3

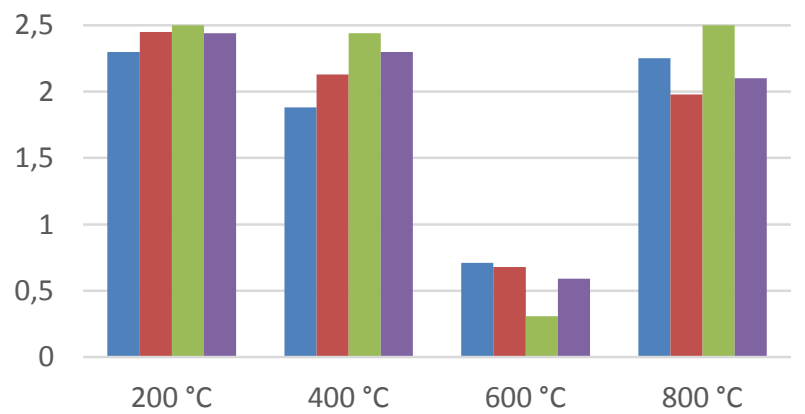

Смесь 5 Смесь 6 Смесь 7 Смесь 8

Рис. 2. Остаточная прочность жидкостекольных образцов при содержании 4 \% жидкого стекла 


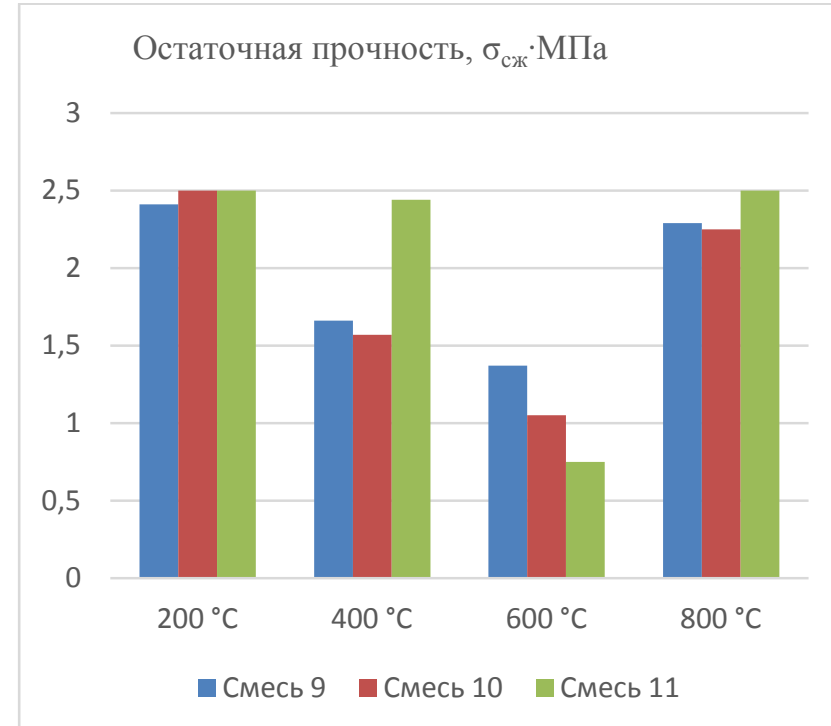

Рис. 3. Остаточная прочность жидкостекольных образцов при содержании 5 \% жидкого стекла

Из данных, представленных на графиках, можно сделать вывод о том, что при температуpe $180{ }^{\circ} \mathrm{C}$ остаточная прочность образцов находится в пределах 2,5 МПа, без явного преимущества какого-либо образца при температуре $400{ }^{\circ} \mathrm{C}$ остаточная прочность образцов падает и достигает своего минимума при температуре $600{ }^{\circ} \mathrm{C}$. При повышении температуры нагрева до $800{ }^{\circ} \mathrm{C}$ был зафиксирован рост остаточной проч-

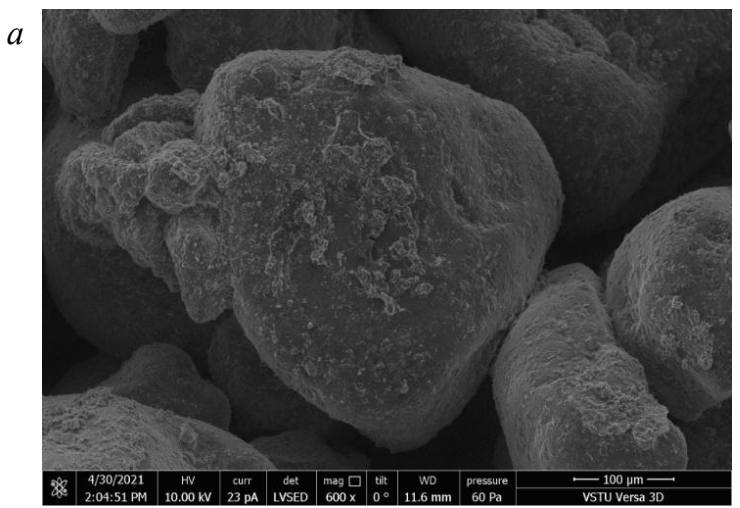

B

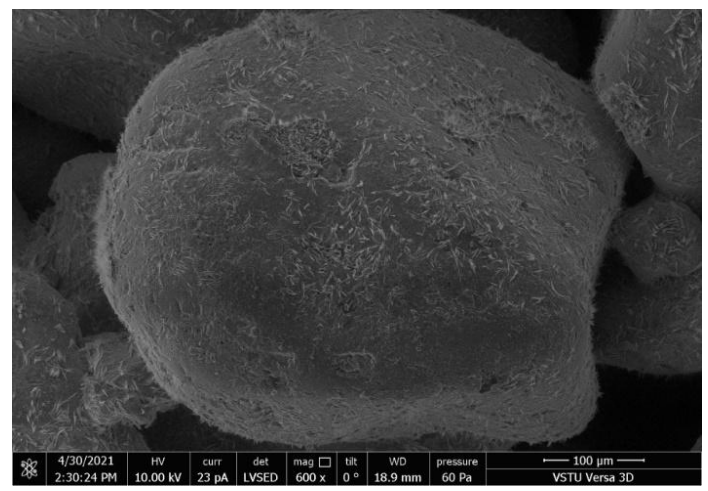

ности образцов, связанный со способностью связующего расплавляться при температуре свыше $793^{\circ} \mathrm{C}$, сопровождая сплавление дефектов [2].

По результатам испытаний выявлено, что образцы, изготовленные из смеси, содержащей в своем составе помимо наполнителя $3 \%$ жидкого стекла и $2 \%$ ощелаченных лигносульфонатов технических, имеют наименьшую остаточную прочность.

6

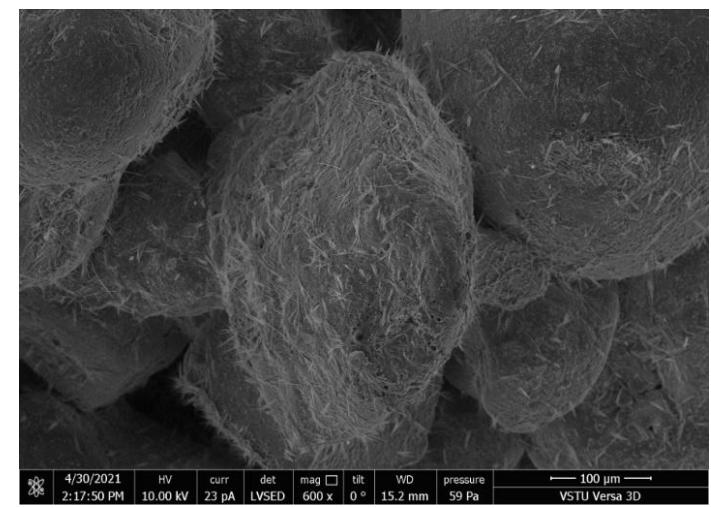

2

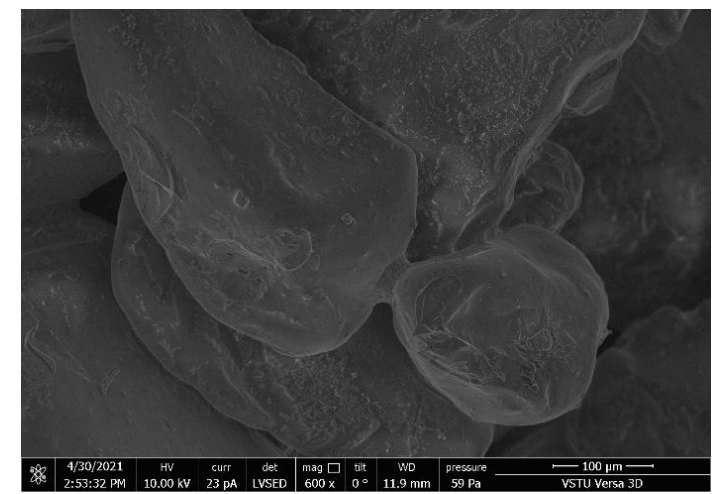

Рис. 4. Структура жидкостекольных пленок на зернах огнеупорного кварцевого наполнителя: $a-180{ }^{\circ} \mathrm{C}$ (увеличение х600); $\sigma-400{ }^{\circ} \mathrm{C}$ (увеличение х600); $в-600{ }^{\circ} \mathrm{C}$ (увеличение х600); $2-800{ }^{\circ} \mathrm{C}$ (увеличение х600) 
Далее проводилось исследование структуры пленок силикатного связующего на поверхности огнеупорного наполнителя с помощью двухлучевого электронного сканирующего микроскопа «Versa 3D». На рис. 4 представлены фотографии структуры жидкостекольной смеси, имеющей наименьший показатель остаточной прочности.

Как видно из рис. 4, структура силикатной пленки при нагреве образцов в интервале температур имеет дефекты в виде кристаллов карбонатов натрия, протекающей в результате химической реакции [13]:

$$
\mathrm{CO}_{2}+\mathrm{Na}_{2} \mathrm{O} \rightarrow \mathrm{Na}_{2} \mathrm{CO}_{3} .
$$

Данная реакция протекает в результате процесса карбонизации при выделении $\mathrm{CO}_{2}$ при деструкции органической составляющей, входящей в состав ОЛСТ. Наличие данных дефектов в интервале температур $400-600{ }^{\circ} \mathrm{C}$ положительно влияет на остаточную прочность, так как при сплавлении силикатной пленки при температуре свыше $793{ }^{\circ} \mathrm{C}$ приводит к нарушению равномерности распределения пленки водного силиката натрия на поверхности зерен огнеупорного наполнителя, способствующей снижению остаточной прочности.

\section{Выводы}

Исследования показали, что использование ощелаченных лигносульфонатов технических в составе жидкостекольных смесей положительно влияет на физико-механические свойства жидкостекольных смесей.

Экспериментально установлено соотношение вводимых в смесь жидкого стекла - $3 \%$ и ОЛСТ - $2 \%$, что подтверждается наименьшим показателем остаточной прочности при высокотемпературном воздействии.

Установлено, что при добавлении ощелаченных лигносульфонатов технических снижение остаточной прочности образцов характеризуется образованием кристаллов карбонатов натрия, сплавление которых приводит к нарушению равномерности распределения пленки водного силиката натрия на поверхности зерен огнеупорного наполнителя.

\section{БИБЛИОГРАФИЧЕСКИЙ СПИСОК}

1. Лясс, А. М. Быстротвердеющие формовочные смеси / А. М. Лясс. - М. : Машиностроение, 1965. - 332 с.

2. Жуковский, C. С. Технология литейного производства: формовочные и стержневые смеси / С. С. Жуковский, А. Н. Болдин. - Брянск : БГТУ, 2002. - 470 с.

3. Жуковский, C. C. Формы и стержни из холоднотвердеющих смесей / С. С. Жуковский, А. М. Лясс. - М. Машиностроение, 1978. - 222 с.

4. Формовочные материалы и технология литейной формы : Справочник / С. С. Жуковский [и др.]. - М. : Машиностроение, 1993. - 432 с.

5. Исследование структуры пленки водного силиката натрия на поверхности хромитового наполнителя при различных способах отверждения / Н. А. Кидалов, Н. В. Григорьева, А. С. Адамова, Д. А. Затямин // Заготовительные производства в машиностроении. - 2020. - Т. 18, № 11. 483-487.

6. Влияние способов отверждения жидкостекольной смеси на прочностные характеристики и структуру литейной формы / Н. А. Кидалов, Н. В. Григорьева, А. С. Адамова, Д. А. Затямин // Известия ВолгГТУ : научный журнал № 10 (233) / ВолгГТУ. - Волгоград, 2019. - (Серия «Проблемы материаловедения, сварки и прочности в машиностроении»). - С. 78-81.

7. Кидалов, Н. А. Effect of a Carbonaceous Additive on the Structure of an Aqueous Sodium Silicate Film on the Surface of a Refractory Chromite Filler / Н. А. Кидалов, Н. В. Григорьева, А. С. Адамова // IOP Conference Series: Materials Science and Engineering. Vol. 969 : International Russian Conference on Materials Science and Metallurgical Technology (RusMetalCon 2020) (Chelyabinsk, Russian Federation, 22-24 September 2020). - [IOP Publishing], 2020. $7 \mathrm{p}$.

8. Иванов, H. X. Применение смесей с уменьшенным количеством жидкого стекла / Н. Х. Иванов // Литейное производство. - 1961. - № 12. - С. 13-14.

9. Иванов, Н. Х. Активированные формовочные смеси / Н. Х. Иванов, В. Ф. Печеный // Литейное производство. 1975. - № 1. - C. 4.

10. A. c. SU1766576A1 CCCP, МПК В22C1/00 В22C1/20 В22C5/04. Способ реагентной активации формовочных и стержневых смесей / Н. Х. Иванов. № 4863381/02 ; заявл.10.07.90 ; опубл. 07.10.92.

11. ГОСТ 23409.7-78. Пески формовочные, смеси формовочные и стержневые. Методы определения прочности при сжатии, растяжении, изгибе и срезе (с изменениями № 1, 2). - Взамен ГОСТ 2189-62 в части разд. IV ; введ. 01.01.80. - М. : Изд-во стандартов, 1986. - 6 с.

12. ГОСТ 23409.9-78. Смеси формовочные и стержневые. Метод определения осыпаемости. - Взамен ГОСТ 2189-62 в части разд. V ; введ. 01.01.1980. - М. : Изд-во стандартов, 1986. - 2 с.

13. Некрасов, Б. В. Основы общей химии / Б. В. Некрасов. - М., 1973. - Т. 1. - С. 494. 